Ethos: Jurnal Penelitian dan Pengabdian kepada Masyarakat, Vol 9, No.1, Januari 2021: 1-7

\title{
RAdiUs dan WAKTU Tempuh Studi AKSesibilitas Pedestrian TERHADAP SARANa Prasarana Umum
}

\author{
${ }^{1}$ Fachmy Sugih Pradifta, ${ }^{2}$ Emmy Ulfah Utami
}

${ }^{I}$ Program Studi Perencanaan Wilayah dan Kota, Universitas Islam Bandung, Jawa Barat, Indonesia

${ }^{2}$ Institut Teknologi Bandung, Jawa Barat, Indonesia

email: '1fachmy.pradifta@unisba.ac.id, 2emiulfah@gmail.com

\begin{abstract}
The provision of public amenities and infrastructures are crucial in creating a livable housing environment as mandated in Housing and Settlement Act No. 1/2011. One of the commonly used criteria in public amenities and infrastructures' planning standard is service area radius which draws as an imaginary circled line with the amenities as it's center. The radius principles have a problematic application on the pedestrianly impermeable urban fabric. This research trying to measure several categories basic of public amenities accessibility based on traveling time, categorized in 3 (three) ranges: the direct living environment, the quartier daily supply, and the district periodic supply. The method used in this research is 2 (two) dimensional distance measurement of public amenities entrance to buildings entrance which located on its service area. Turangga Sub-district in Lengkong District, Bandung City is used as a case study. It is hoped that this study could give valuable advice on the planning and development control of public amenities and infrastructures provision in Bandung City by considering the walkability factor.
\end{abstract}

Keywords: Pedestrian, townscape, permeability, walkability, public amenities and infrastructures, service area radius.

\begin{abstract}
Abstrak. Penyediaan sarana, prasarana dan utilitas (SPU) di perkotaan merupakan aspek penting dalam upaya mewujudkan perumahan yang layak huni sesuai dengan amanat UU No. 1 / 2011 tentang Perumahan dan Kawasan Permukiman. Salahsatu kriteria dalam standar perencanaan yang umum digunakan dalam perletakkan SPU adalah radius pelayanan berupa lingkaran imajiner dengan SPU sebagai pusatnya. Penerapan radius pelayanan mengalami permasalahan ketika pola gubahan ruang kota (urban fabric) yang ada tidak memiliki permeabilitas yang baik terhadap pejalan kaki. Penelitian ini mencoba mengukur aksesibilitas dari beberapa kategori SPU tingkat lingkungan berdasarkan waktu tempuh berjalan kaki yang dikategorikan kedalam 3 (tiga) rentang, lingkungan hunian, lingkungan kebutuhan dasar, dan lingkungan kebutuhan berkala. Metode yang digunakan adalah pengukuran jarak secara 2 (dua) dimensi pada peta digital dari pintu akses SPU menuju pintu masuk rumah-rumah yang berada pada jangkauan pelayanannya. Studi kasus yang digunakan adalah Kelurahan Turangga, Kecamatan Lengkong, Kota Bandung. Studi ini diharapkan dapat memberikan masukan terhadap perencanaan dan pengendalian pembangunan SPU di Kota Bandung dengan memperhatikan faktor keterjangkauan dengan berjalan kaki (walkability).
\end{abstract}

Kata Kunci. Pejalan kaki, townscape, permeabilitas, walkability, sarana dan prasarana umum, radius pelayanan.

\section{Pendahuluan}

Pentingnya menciptakan sebuah lingkungan yang ramah pejalan kaki (walkable) telah ditekankan dalam berbagai paradigma perencanaan kota kontemporer seperti new urbanism, smart growth, dan China's 15-min 
Walkable Neighborhoods (Weng et al., 2019). Hal ini membuat walkability mendapatkan perhatian khusus dalam perencanaan sebuah lingkungan perkotaan. Walkability didefinisikan sebagai sebuah usaha dimana lingkungan perkotaan dirancang agar ramah pejalan kaki (Moura, Cambra, \& Gonçalves, 2017). Manfaat dari lingkungan yang walkable diyakini dapat meningkatkan kesehatan penghuninya dan mencegah penyakit kronis serta obesitas (Weng et al., 2019).

Salah satu faktor yang menjadi pertimbangan dalam perencanaan lingkungan yang ramah pejalan kaki adalah ketersediaan dan keterjangkauan sarana, prasarana dan utilitas (SPU) (Martínez-Martínez \& Ramírez-López, 2018). Perencanaan sarana, prasarana dan utilitas (SPU) yang baik akan mendukung pembentukan pola dan struktur kota yang efisien dalam melayani kebutuhan warga kota (Djoeffan \& Mukhsin, 2003).

Aksesibilitas terhadap SPU di lingkungan perumahan telah disadari sejak dicetuskannya konsep neighborhood unit pada tahun 1920-an sebagai model lingkungan perkotaan yang self-contained dan berorientasi komunitas. Dalam konteks Indonesia, adaptasi dari konsep neighborhood unit diadopsi oleh SNI 03-1733-2004 sebagai standar perencanaan lingkungan perumahan di perkotaan.

Kriteria utama perencanaan SPU pada SNI 03-1733-2004 adalah jumlah penduduk dan radius area yang dilayani untuk setiap skala pelayanan (RT, RW, Kelurahan, Kecamatan, Kota, dsb.). Radius pelayanan digambarkan sebagai area dalam lingkaran imajiner dengan lokasi SPU sebagai titik pusatnya.

Radius pelayanan yang secara normatif berbentuk bulat sempurna, secara praktikal cenderung sulit diterapkan. Aksesibilitas SPU sangat dipengaruhi oleh pola gubahan ruang kota (urban fabric) berupa jalan, blok perkotaan, dan hambatan-hambatan yang terjadi pada mobilitas penghuni dalam rangka memenuhi kebutuhan sehari-hari (Wohl, 2017). Hal ini mengakibatkan jangkauan SPU tersebut dapat berbeda dengan radius normatifnya jika mempertimbangkan waktu tempuh untuk mencapainya.

Untuk dapat merencanakan SPU yang ramah pejalan kaki, sebuah perencanaan Tata Bangunan yang tidak hanya menyangkut perancangan bangunan sebagai bangunan tunggal, tetapi juga lingkungan sekitarnya, termasuk sarana dan prasarana (Hindersah, Agustina, \& Indratno, 2017) perlu dilakukan. Dengan demikian, perencanaan SPU, perancangan urban fabric, dan Tata Bangunan merupakan satu kesatuan dalam menciptakan lingkungan yang ramah pejalan kaki.

Penelitian ini mencoba mengukur aksesibilitas dari beberapa kategori SPU tingkat lingkungan berdasarkan waktu tempuh berjalan kaki penghuni dari tempat tinggalnya menuju SPU tersebut. Hasil dari pengukuran tersebut kemudian dibandingkan dengan standar radius normatifnya. Tingkat permeabilitas blok sebagai salah satu prinsip perancangan tata bangunan yang ramah pejalan kaki diharapkan akan dapat diamati melalui teknik mapping dan tracing dari rute yang dilalui.

\section{Metode}

\section{Lingkup Wilayah}

Lokasi studi yang dipilih adalah Kelurahan Turangga, Kecamatan Lengkong, Kota Bandung. Pemilihan lokasi mempertimbangkan konteksnya yang merupakan kawasan perumahan yang berada di tengah kota dengan fasilitas yang cukup lengkap tersebar secara merata, namun terdapat beberapa hambatan yang berpotensi mengurangi aksesibilitas pejalan kaki seperti 
penutupan jalan lingkungan. Sedangkan pertimbangan memilih skala kelurahan adalah untuk menyesuaikan dengan skala SPU yang dianalisis yaitu SPU skala lingkungan (basic needs).

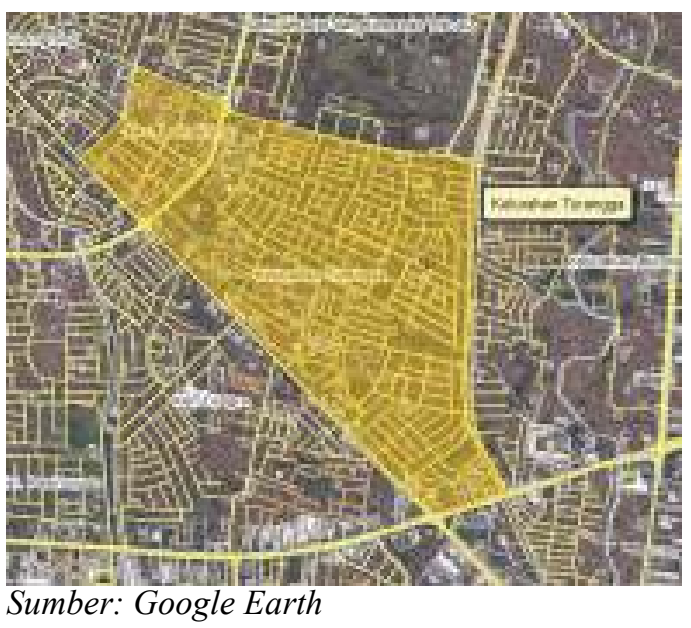

Gambar 1. Peta Lokasi Penelitian

\section{Townscape Analysis}

Penelitian ini menggunakan metode analisis townscape. Townscape dapat diartikan sebagai relasi antara bangunan dan ruang di sekitarnya yang membentuk sebuah citra dari kingkungan tersebut. Salah satu aspek dalam analisis townscape adalah studi permeabilitas. Studi permeabilitas berkontribusi dalam rancang kota berupa: (1) memberikan kemudahan akses terhadap ruang publik; (2) mengarahkan desain pertemuan antara ruang publik dengan area properti pribadi yang lebih privat; dan (3) memberikan pilihan pada pengguna (environmental determinism, possibilism, dan probabilism) (Lynch, 1981).

\section{Mapping dan Tracing}

Teknik yang digunakan adalah dengan mapping dan tracing (Gehl \& Svarre, 2013). Mapping dilakukan untuk memetakan persebaran SPU di lokasi penelitian serta menunjukkan kavelingkaveling yang dapat mengakses SPU tersebut dengan berjalan kaki. Peta dasar yang digunakan adalah peta garis Kota Bandung dalam bentuk file CAD.

Tracing digunakan untuk mengetahui kaveling mana saja yang terlayani berdasarkan rute terdekat berjalan kaki. Rute diidentifikasi dengan cara menarik garis sesuai kondisi di lapangan dari pintu masuk kaveling ke pintu masuk utama SPU. Terdapat tiga tingkatan skala lingkungan berdasarkan waktu dan jarak tempuh berjalan kaki yaitu: (1) lingkungan hunian (the direct living environment) dengan waktu tempuh 5 menit atau maksimum 200 meter; (2) lingkungan kebutuhan dasar (the quartier, daily supply-and contactrange) dengan waktu tempuh 10 menit atau maksimum 600 meter; dan (3) lingkungan kebutuhan berkala (the district, or other periodic supply range) dengan waktu tempuh 17 menit atau maksimum 1.000 meter (Prinz, 1999).

Setiap rentang waktu dan jarak tempuh diberi gradasi warna yang menunjukkan kaveling mana saja yang berada dalam rentang tersebut. Hasilnya kemudian dibandingkan dengan radius pelayanan sebagai standar normatif perencanaan SPU.

Studi ini hanya mempertimbangkan waktu tempuh berjalan kaki dengan jarak yang diasumsikan dapat ditempuh dengan kecepatan berjalan kaki normal. Beberapa faktor lain yang dapat mempengaruhi tingkat walkability seperti kondisi sarana pejalan kaki seperti trotoar dan perkerasan lainnya serta kualitas visual lingkungan sepanjang rute pejalan kaki tidak dipertimbangkan dalam studi ini. Selain itu terdapat kemungkinan lain berupa preferensi individual terhadap pemilihan rute dan kualitas SPU disederhanakan menjadi rute terpendek dan SPU terdekat yang dapat diakses dengan berjalan kaki. 


\section{Hasil dan Pembahasan}

Jenis SPU yang diidentifikasi di lokasi penelitian ini adalah kebutuhankebutuhan dasar skala lingkungan yang meliputi: (1) perdagangan (warung, toko kelontong, minimarket, pasar tradisional/modern); (2) pendidikan dasar (PAUD, TK, dan SD); (3) kesehatan (rawat jalan rumah sakit, puskesmas, klinik, praktek dokter); dan (4) ruang terbuka publik (taman RT, RW, kelurahan, taman kota). Letak SPU diidentifikasi melalui survey primer dan sekunder. Analisis aksesibilitas berdasarkan rentang waktu dan jarak tempuh disajikan dalam peta tematik keempat jenis SPU tersebut.

\section{Sarana Perdagangan}

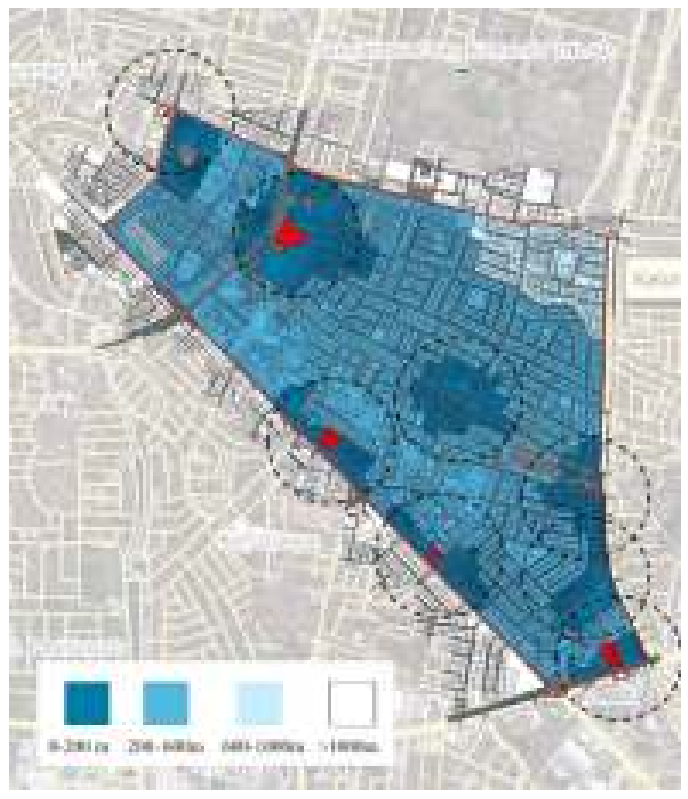

Gambar 2. Analisis Aksesibilitas Pejalan Kaki Sarana Perdagangan

\section{Hasil analisis aksesibilitas pejalan kaki sarana perdagangan menunjukkan untuk rentang lingkungan kebutuhan dasar, semua area di dalam lokasi studi terlayani oleh sarana perdagangan. Kecuali sebagian kecil area di Timur Laut yang tidak memiliki sarana perdagangan dalam rentang lingkungan kebutuhan dasar.}

Perbedaan aksesibilitas rentang lingkungan hunian terlihat pada SPU yang berada di perimeter dengan yang berada di bagian dalam area studi. Pada SPU yang terdapat di bagian dalam area studi memiliki aksesibilitas yang cukup baik sehingga waktu tempuh pejalan kakinya memiliki deviasi yang kecil dengan radius pelayanannya. Sedangkan pada SPU yang terletak di perimeter, umumnya terdapat di jalan utama, memiliki aksesibilitas pejalan kaki yang kurang baik sehingga tidak dapat diakses oleh kaveling di belakangnya.

\section{Sarana Pendidikan Dasar}

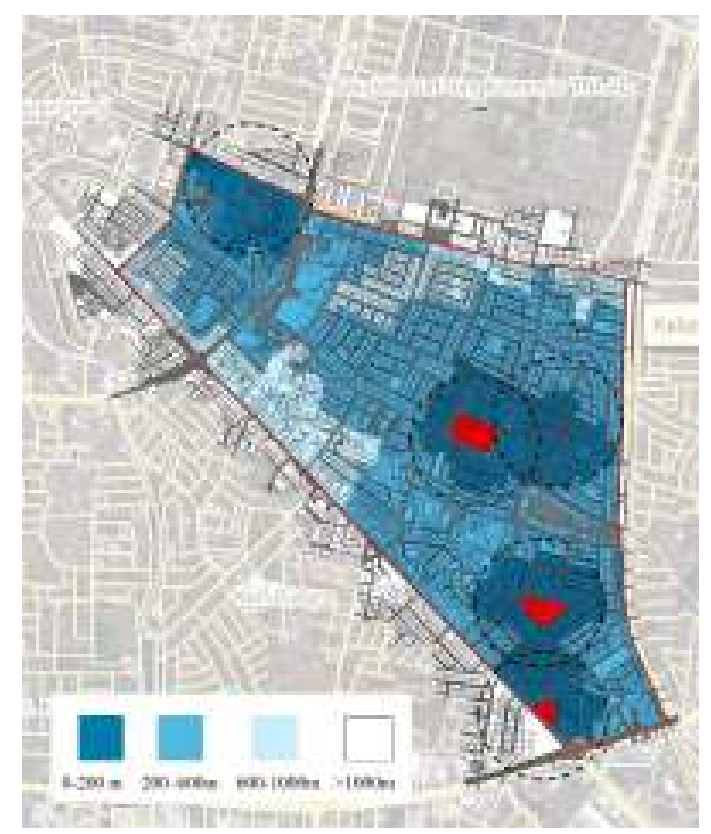

Gambar 3. Analisis Aksesibilitas Sarana Pendidikan Dasar

Analisis aksesibilitas sarana pendidikan dasar menunjukkan terdapat sejumlah area yang signifikan yang tidak memiliki sarana pendidikan dasar dalam jangkauan rentang lingkungan kebutuhan dasar. Dapat dikatakan area studi memiliki kekurangan jumlah sarana pendidikan dasar yang memadai, terutama di bagian Barat Laut area studi.

Namun demikian, pada sarana pendidikan yang ada, umumnya memiliki aksesibilitas yang baik dengan deviasi antara radius pelayanan dengan 
waktu tempuh pejalan kaki lingkungan hunian yang tidak terlalu besar. Hal ini cukup sesuai dengan kriteria dalam SNI 03-1733-2004 mengenai sarana pendidikan dasar dimana lokasi yang dianjurkan adalah di tengah-tengah perumahan. Hal ini dimaksudkan agar siswa dapat berjalan kaki pada lingkungan yang relatif aman dengan jarak tempuh yang dekat.

\section{Sarana Kesehatan}

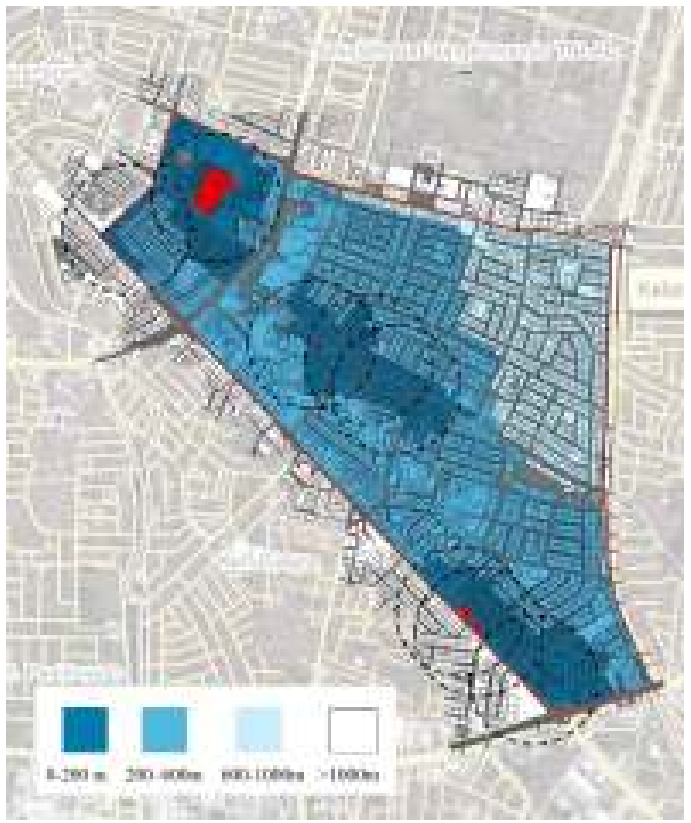

Gambar 4. Analisis Aksesibilitas Pejalan Kaki Sarana Kesehatan

Analisis aksesibilitas sarana kesehatan memperlihatkan ketidakmerataan persebaran sarana kesehatan dengan sejumlah area di Timur Laut yang tidak mendapatkan akses yang terjangkau dalam rentang kebutuhan dasar. Area studi perlu menambah sarana-sarana pelayanan skala lingkungan seperti balai kesehatan/klinik dan tempat praktek dokter umum.

Sementara pada sarana kesehatan yang berada di bagian dalam area studi memiliki aksesibilitas yang kurang baik dengan deviasi antara radius pelayanan dengan waktu tempuh pejalan kaki lingkungan hunian hampir mencapai
$50 \%$. Keberadaannya pun terlalu mengelompok sehingga radius pelayanan maupun rentang jangkauannya saling beririsan.

\section{Ruang Terbuka Publik}

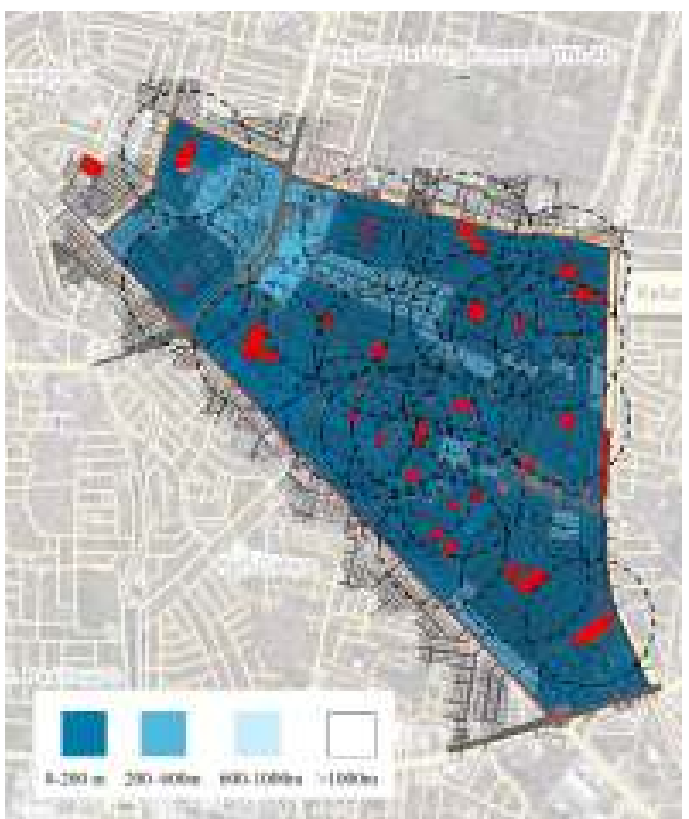

Gambar 5. Analisis Aksesibilitas Ruang Terbuka Publik

Keberadaan Ruang Terbuka Hijau (RTH) lingkungan di setiap RT/RW berkontribusi terhadap aksesibilitas yang baik terhadap ruang terbuka publik di seluruh area studi. Lokasi RTH yang berada di bagian dalam area studi dengan hambatan yang lebih sedikit dibandingkan jalan utama membantu dalam memudahkan aksesibilitas pejalan kaki.

Keberadaan RTH yang mudah diakses sangat penting dalam menciptakan kesehatan mental penghuninya. Kuantitas RTH yang memadai perlu diimbangi dengan kualitas yang baik untuk mewujudkan hal tersebut seperti proses perencanaan, jenis RTH, dan pengelolaan (Carmona, 2019; Francis, Wood, Knuiman, \& Giles-Corti, 2012).

Berdasarkan analisis aksesibilitas setiap SPU ditemukan bahwa SPU yang berada di bagian dalam 
area studi umumnya memiliki permeabilitas yang lebih baik bagi pejalan kaki dibandingkan dengan yang terletak di jalan utama. Hal ini dikarenakan ukuran blok perkotaan yang lebih kecil di bagian dalam area studi sehingga meningkatkan jumlah persimpangan dan alternatif pemilihan rute terpendek menuju SPU. Kurang baiknya aksesibilitas SPU di jalan utama disebabkan oleh terbatasnya rute yang dapat dipilih dengan jarak antar persimpangan yang panjang sehingga waktu tempuh yang dibutuhkan semakin besar. Namun hal ini dapat dipahami karena umumnya SPU yang berada di jalan utama ditujukan untuk skala pelayanan yang lebih luas, sehingga moda transportasi yang digunakan untuk mencapainya adalah dengan kendaraan bermotor.

Hambatan akesibilitas di bagian dalam area studi yang sering ditemui adalah adanya portal-portal lingkungan berupa pagar tinggi yang tidak memiliki akses bagi pejalan kaki. Keberadaan portal ini menurunkan tingkat permeabilitas blok karena memaksa pejalan kaki untuk mencari rute lain yang lebih panjang sehingga berimplikasi terhadap waktu tempuh yang lebih lama.

\section{Kesimpulan dan Saran}

Kesadaran mengenai keberlanjutan lingkungan semakin besar dalam perencanaan dan perancangan kota. Oleh karena itu, sangat penting untuk mengarahkan perencanaan lingkungan perumahan perkotaan yang meminimalisasi penggunaan kendaraan pribadi, terutama dalam mengakses kebutuhan-kebutuhan dasar. Perancangan jaringan SPU yang aksesibel harus dipandang sebagai salah satu unsur pembentuk lingkungan yang ramah pejalan kaki dan pada akhirnya menciptakan lingkungan yang layak huni dan berkelanjutan.
Standar normatif dengan menggunakan radius pelayanan perlu dikomparasi dengan analisis waktu tempuh melalui studi aksesibilitas untuk mengetahui efektivitas penempatan setiap SPU. Studi mengenai permeabilitas urban fabric dari sudut pandang pejalan kaki perlu dilakukan sebagai evaluasi baik dalam tahap perencanaan maupun pelaksanaan.

Hasil dari studi aksesibilitas di kawasan studi dapat dipergunakan untuk menentukan strategi peningkatan pelayanan SPU, yaitu dengan: (1) menambah jumlah SPU untuk melayani area yang kurang mendapatkan akses; (2) memperbaiki tingkat permeabilitas blok melalui pembebasan hambatanhambatan pejalan kaki seperti membuka portal-portal jalan yang tidak ramah pejalan kaki, atau; (3) membuat jalanjalan pintas khusus pejalan kaki untuk memperpendek waktu tempuh.

Kekurangan dari studi ini adalah belum menganalisis pengaruh pelayanan dari SPU yang berada di sekitar lingkup lokasi penelitian yang berpotensi untuk diakses oleh penghuni yang berada dalam area studi.

\section{DAFTAR PUSTAKA}

Carmona, M. (2019). Principles for public space design, planning to do better. Urban Design International, 24(1),

47-59. https://doi.org/10.1057/s41289-0180070-3

Djoeffan, S. H., \& Mukhsin, D. (2003). Inventarisasi Sarana dan Prasarana Permukiman di Lembah Cikapundung. ETHOS: Jurnal Penelitian Dan Pengabdian, 1(2; Juli-Desember), 87-98. https://doi.org/https://doi.org/10.293 13/ethos.v0i0.1611

Francis, J., Wood, L. J., Knuiman, M., \& Giles-Corti, B. (2012). Quality or quantity? Exploring the relationship between Public Open Space 
attributes and mental health in Perth, Western Australia. Social Science and Medicine, 74(10), 1570-1577. https://doi.org/10.1016/j.socscimed. 2012.01.032

Gehl, J., \& Svarre, B. (2013). How to Study Public Life. Washington: Island Press.

Hindersah, H., Agustina, I. H., \& Indratno, I. (2017). Pembelajaran Tata Bangunan dan Lingkungan di Desa Cikole Kecamatan Lembang, Kabupaten Bandung Barat. Ethos (Jurnal Penelitian Dan Pengabdian Masyarakat), 5(2: Juni), 284-290. https://doi.org/https://doi.org/10.293 13/ethos.v5i2.2355

Lynch, K. (1981). A Theory of Good City Form. Massachusetts: The MIT Press.

Martínez-Martínez, O. A., \& RamírezLópez, A. (2018). Walkability and the built environment: validation of the Neighborhood Environment Walkability Scale (NEWS) for urban areas in Mexico. Quality and Quantity, 52(2), 703-718. https://doi.org/10.1007/s11135-0170483-x

Moura, F., Cambra, P., \& Gonçalves, A. B. (2017). Measuring walkability for distinct pedestrian groups with a participatory assessment method: A case study in Lisbon. Landscape and Urban Planning, 157, 282-296. https://doi.org/10.1016/j.landurbplan .2016 .07 .002

Prinz, D. (1999). Städtebau: Band 1:Städtebauliches Entwerfen. Stuttgart: Kohlhammer.

Weng, M., Ding, N., Li, J., Jin, X., Xiao, H., He, Z., \& Su, S. (2019). The 15minute walkable neighborhoods: Measurement, social inequalities and implications for building healthy communities in urban China. Journal of Transport and Health, 13(129),
259-273.

https://doi.org/10.1016/j.jth.2019.05 .005

Wohl, S. (2017). From form to process: Re-conceptualizing Lynch in light of complexity theory. Urban Design International, 22(4), 303-317. https://doi.org/10.1057/s41289-0170048-6 